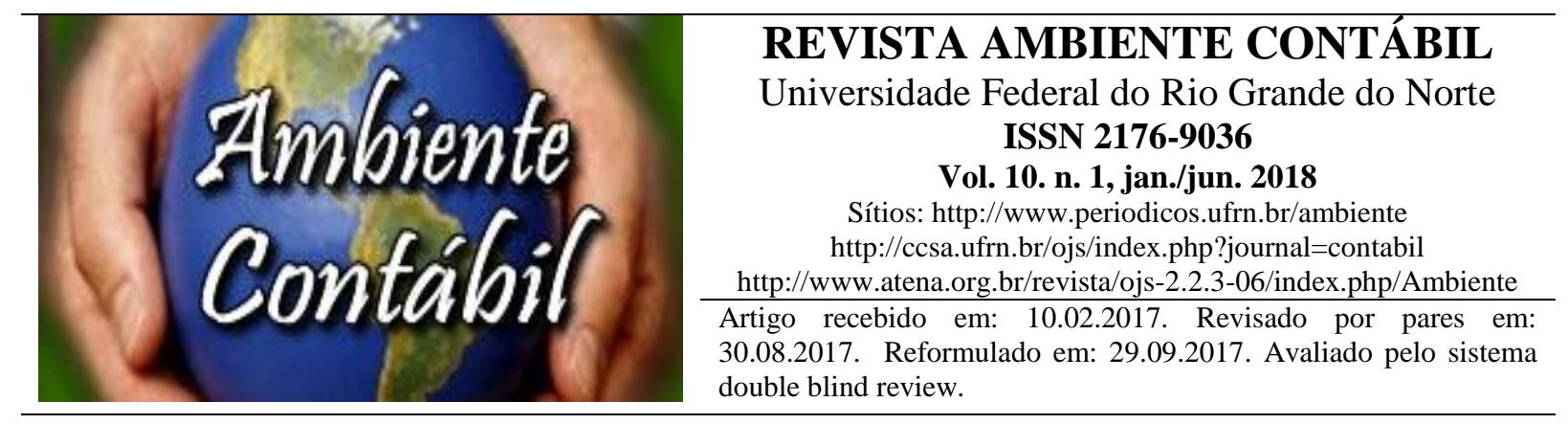

\title{
DEMONSTRAÇÃO DO VALOR ADICIONADO: A EVOLUÇÃO E A DISTRIBUIÇÃO DA RIQUEZA DAS EMPRESAS CATARINENSES LISTADAS NA BM\&FBOVESPA
}

\section{STATEMENT OF VALUE ADDED: THE EVOLUTION AND DISTRIBUTION OF THE WEALTH OF SANTA CATARINA COMPANIES LISTED ON THE BM\&FBOVESPA}

\section{DECLARACIÓN DE VALOR AÑADIDO: EVOLUCIÓN Y DISTRIBUCIÓN DE LA ABUNDANCIA DE SANTA CATARINA QUE FIGURAN LAS EMPRESAS BM\& FBOVESPA}

Autores

Ana Paula Günther Guesser Graduada em Ciências Contábeis pela Universidade do Oeste de Santa Catarina (UNOESC). Endereço: Rua Antônio Nunes Varela, 2600 - Bairro Cordazzo, Joaçaba (SC) - Brasil. CEP: 89.600-000 - Telefone: (49) 99159-7359. Identificadores (ID): Lattes: http://lattes.cnpq.br/4542733298614503

E-mail: anapaulagunther@hotmail.com

Juliana Fedrigo Graduada em Ciências Contábeis pela Universidade do Oeste de Santa Catarina (UNOESC). Endereço: Rua Osvaldo Karloh, Bairro São José, Treze Tílias (SC) - Brasil. CEP: 89.650-000

- Telefone: (49) 99946-0198. E-mail: juliana.fedrigo@bol.com.br

André Carlos Einsweiller

Professor da Universidade do Oeste de Santa Catarina (UNOESC). Especialista em Convergência as Normas Internacionais - IFRS (UNOESC). Endereço: Rua Wilibaldo Vier, $n^{\circ}$ 137, Bairro Vila Alemanha, Luzerna (SC) - Brasil. CEP: 89.609-000. Telefone: (49)

99118-8318.

Identificadores (ID): Lattes http://lattes.cnpq.br/7201675866551544 E-mail: andre.einsweiller@unoesc.edu.br 


\section{RESUMO}

Atualmente, as questões sociais vêm ganhando relevância nas empresas e na sociedade. E utilizar-se de informações das mais variadas naturezas tem comprovadamente produzido efeito financeiro e econômico às células sociais. O presente estudo tem por objetivo classificar segundo os aspectos sociais, financeiros e econômicos os valores gerados e distribuídos, bem como demonstrar os percentuais da distribuição da riqueza das 23 empresas catarinenses de capital aberto, referente aos anos de 2010 a 2015. Quanto à abordagem, o trabalho caracteriza-se como qualitativa com recorrência a recursos quantitativos. Para que os objetivos propostos fossem atingidos, utilizou-se da pesquisa exploratória descritiva. Os dados foram coletados a partir da análise da Demonstração do Valor Adicionado (DVA), considerando os seguintes grupos: pessoal, governo, remuneração de capital de terceiros e próprio. Os resultados evidenciaram que os percentuais mais significativos de distribuição, segundo o segmento mercadológico, estão relacionados a pagamento de despesas com pessoal (aspecto social) e quanto ao ramo de atuação, a distribuição mais relevante está relacionada à remuneração de capitais próprios (aspecto financeiro). Esse artigo possibilita a análise da contribuição econômica das empresas que compõem a amostra, no aspecto de contribuição e interação social. Ainda, é aconselhável que a Demonstração do Valor Adicionado se adapte às necessidades dos usuários.

Palavras-chave: Valor adicionado. Distribuição da riqueza. Empresas catarinenses.

\section{ABSTRACT}

Nowadays, social issues are gaining relevance in companies and in society. And using information of the most varied natures has proven to have produced financial and economic effect to the social cells. The purpose of this study is to classify the values generated and distributed according to social, financial and economic aspects, as well as to demonstrate the percentages of the distribution of the wealth of the 23 Santa Catarina companies, for the years 2010 to 2015. Regarding the approach, the work is characterized as qualitative with recurrence to quantitative resources. In order for the proposed objectives to be achieved, descriptive exploratory research was used. The data were collected from the analysis of the Value Added Demonstration (VAD), considering the following groups: personnel, government, compensation of third-party capital and own. The results showed that the most significant distribution percentages, according to the market segment, are related to the payment of personnel expenses (social aspect) and the most relevant distribution is related to the remuneration of own capital (financial aspect). This article allows the analysis of the economic contribution of the companies that make up the sample, in the aspect of social contribution and interaction. Still, it is advisable that the Value Added Demo adapts to the needs of users.

Keywords: Added value. Distribution of wealth. Companies in Santa Catarina.

\section{RESUMEN}

Actualmente, las cuestiones sociales vienen ganando relevancia en las empresas y en la sociedad. Y el uso de informaciones de las más variadas naturalezas ha demostrado haber producido efecto financiero y económico a las células sociales. El presente estudio tiene por objetivo clasificar según los aspectos sociales, financieros y económicos los valores generados y distribuidos, así como demostrar los porcentajes de la distribución de la riqueza de las 23 empresas catarinenses de capital abierto, referente a los años de 2010 a 2015. En cuanto al abordaje, el trabajo se caracteriza como cualitativa con recurrencia a recursos cuantitativos. Para que los objetivos propuestos fueran alcanzados, se utilizó la investigación exploratoria descriptiva. Los datos fueron recolectados a partir del análisis de la Demostración del Valor Añadido (DVA), considerando los siguientes grupos: personal, gobierno, 
remuneración de capital de terceros y propio. Los resultados evidenciaron que los porcentajes más significativos de distribución, según el segmento mercadológico, están relacionados con el pago de gastos con personal (aspecto social) y en cuanto al ramo de actuación, la distribución más relevante está relacionada a la remuneración de capitales propios (aspecto financiero). Este artículo posibilita el análisis de la contribución económica de las empresas que componen la muestra, en el aspecto de contribución e interacción social. Además, es aconsejable que la Demostración del Valor Añadido se adapte a las necesidades de los usuarios.

Palabras clave: Valor añadido. Distribución de la riqueza. Empresas catarinenses.

\section{INTRODUÇÃO}

Em um ambiente econômico e financeiro repleto de informações, sejam elas de caráter especulativo ou realistas, buscar novos diferenciais pelos diversos métodos de análise, controle e estratégias, mostram-se fundamentais para a continuidade dos negócios. Muitas são as exigências, tanto de caráter interno, quanto externo, aplicadas à rotina das empresas com vistas à manutenção e expansão de suas atividades operacionais, e que acarretam o aumento da competitividade entre os setores, independente do porte das entidades.

Por meio da DVA (Demonstração de Valor Adicionado) é possível perceber a contribuição econômica da entidade para cada segmento com o qual ela se relaciona (KROETZ, 2000). A possibilidade de extrair da DVA, isoladamente ou em conjunto com outros demonstrativos, tantas informações sociais quanto econômicas, comprova a utilidade da mesma para todo conjunto de usuários das informações contábeis (DALMÁCIO, 2004).

Dessa forma, surge a necessidade de apropriar-se dos mais variados tipos de informações, como uma maneira de diferenciar-se dos demais. Dentre elas pode-se ressaltar a importância das ações de controle e gestão advindas da análise decorrente da evidenciação da riqueza gerada pela entidade e seu impacto na sociedade onde está inserida.

A contabilidade através de seus demonstrativos possui informações que representam valiosa ferramenta de gestão, bem como dispõe de elementos comprobatórios eficazes, que possibilitam a evidenciação da geração e distribuição de valores. Como fonte de informações, a Demonstração do Valor Adicionado (DVA) tem esse papel, evidenciando a preocupação crescente com o aspecto social das entidades, bem como vislumbra e possibilita a análise de suas atividades através de outro enfoque, onde é possível fornecer e abstrair informações a todos os que contribuíram e usufruem dos resultados alcançados.

Desta maneira após a obrigatoriedade da divulgação da Demonstração do Valor Adicionado (DVA), implementada pela Lei 11.638/2007 (BRASIL, 2007) e norteada pelo Comitê de Pronunciamentos Contábeis CPC 09 de 2008, torna-se relevante sua análise após o período de implementação da divulgação da referida demonstração.

Ainda, de modo que se tem por objetivo classificar as informações sobre os valores distribuídos com base na Demonstração do Valor Adicionado (DVA) dessas entidades para que essas constituam base para análise permitindo a elucidação do seguinte problema de pesquisa: qual a distribuição e a evolução da riqueza das empresas catarinenses de capital aberto listadas na BM\&FBOVESPA expressas no Demonstrativo do Valor Adicionado?

Dessa forma, o presente estudo tem como objetivo analisar e descrever a distribuição e evolução da riqueza das entidades de capital aberto que comercializam suas ações na BM\&FBOVESPA, cuja sede esteja localizada no estado de Santa Catarina, durante o lapso temporal de seis anos, de 2010 a 2015.

O Estado de Santa Catarina se destaca das demais unidades federativas no que tange a diversidade dos ramos de atuação das empresas do estado, essa diversidade aliada à

Revista Ambiente Contábil - ISSN 2176-9036 - UFRN - Natal-RN. v. 10. n. 1, p. 200 - 222, jan./jun. 2018. 
capacidade produtiva efetiva beneficia a economia do estado como um todo, repercutindo na geração de empregos e no aumento dos indicadores sócio econômicos.

Segundo relatório do Serviço Brasileiro de Apoio às Micro e Pequenas Empresas (SEBRAE, 2013); o estado de Santa Catarina possui uma agricultura com potencial significativo, baseada em minifúndios rurais, possui vasto parque industrial atuante, considerado o quarto maior do país com relação ao número de empresas.

Indústrias de grande porte e pequenas empresas espalham-se, fazendo do estado de Santa Catarina a sexta maior economia brasileira pelo tamanho de seu Produto Interno Bruto que em 2013 representava R \$ 214,217 bilhões (ELIZARDO, NAIME, 2015).

O presente estudo deste demonstrativo se justifica pela necessidade de agregar valores sociais a métodos de avaliação econômicos, visto que, a estrutura do demonstrativo nos permite avaliar as fontes de recursos e sua distribuição, sendo que a abordagem social dos impactos das atividades das organizações é assunto de destaque no contexto social.

A delimitação territorial é justificada pela quantidade relevante e, diversidade das entidades que negociam suas ações na BM\&FBOVESPA, sendo que a amostra é composta por 23 entidades que atuam nos ramos de indústria, comércio e serviços. Quanto ao lapso temporal esse foi estabelecido por abranger anos de grandes mudanças no cenário econômico brasileiro e pretende-se analisar as variações dos indicadores nos períodos de 2010 a 2015.

A DVA ainda permite contribuir para o desenvolvimento econômico social das empresas, quanto uma empresa é capaz de contribuir para um município ou região, bem como na eficiência quanto aos fatores de produção, pautado pelo cálculo do PIB.

O artigo permitiu contribuir para a análise e compreensão das distribuições das riquezas ocorridas pelas empresas do estudo, e de que forma cada entidade foi capaz de colaborar no aspecto social, econômico e financeiro. Também agrega base teórica para futuros estudos que possui como tema a demonstração do valor adicionado sobre o enfoque do estudo da distribuição da riqueza.

Além desta breve introdução, este trabalho está dividido em mais quatro seções. A segunda seção apresenta a fundamentação teórica que dá sustentação ao artigo. Na seção três são descritos os procedimentos metodológicos. A seção quatro apresenta os resultados do estudo e a seção cinco apresenta as considerações finais.

\section{FUNDAMENTAÇÃO TEÓRICA}

Para fundamentação do referido estudo são abordados estudos sobre a demonstração do valor adicionado, conceitos de valor adicionado, geração de riqueza e a distribuição do valor adicionado, bem como estudos anteriores.

\subsection{DEMONSTRAÇÃO DO VALOR ADICIONADO}

A Demonstração do Valor Adicionado (DVA) surgiu na Europa, principalmente pela influência de países como Inglaterra, França e Alemanha em virtude do surgimento de movimentos sociais iniciados na década de 1960, século XX. Sua finalidade é evidenciar como o valor adicionado foi produzido pela entidade, durante determinado período e, como está distribuído aos sócios, empregados, demais credores e a parcela pertencente ao governo.

A DVA, no Brasil, teve sua inclusão no balanço social, em 2002, quando este demonstrativo, que segue o modelo aplicado pelo IBASE, foi reformulado. A DVA é um componente fundamental que consta no balanço social (ASSAF NETO, 2010).

Neste contexto, surgiu a Demonstração do Valor Adicionado (DVA), relatório contábil que considera as atividades da empresa como um esforço coletivo de vários grupos de pessoas e apresenta o valor da riqueza criada distribuída entre esses grupos. (DE LUCA, 1996).

Revista Ambiente Contábil - ISSN 2176-9036 - UFRN - Natal-RN. v. 10. n. 1, p. 200 - 222, jan./jun. 2018. 


\begin{abstract}
De acordo com o Pronunciamento Técnico $\mathrm{n}^{\circ} 09$ do Comitê de Pronunciamentos Contábeis - CPC:

[...] essa demonstração proporciona o conhecimento de informações de natureza econômica e social e oferece a possibilidade de melhor avaliação das atividades da entidade dentro da sociedade na qual está inserida. A decisão de recebimento por uma comunidade (Município, Estado e a própria Federação) de investimento pode ter nessa demonstração um instrumento de extrema utilidade e com informações que, por exemplo, a demonstração de resultados por si só não é capaz de oferecer.
\end{abstract}

Santos (2003) considera a DVA mais abrangente que a Demonstração do Resultado do Exercício (DRE), porque a DVA mostra a forma como a riqueza é distribuída através de impostos pagos ao governo, juros e aluguéis destinados a financiadores externos, remunerações pagas aos trabalhadores e lucros e dividendos (ou juros sobre o capital próprio, como previsto na legislação brasileira) atribuídos aos proprietários, sócios e acionistas.

Vale ressaltar que a DVA não substitui, nem invalida, qualquer outro relatório contábil, ao contrário, complementa e reforça as informações prestadas nas demais peças contábeis, inclusive na DRE (CUNHA et al., 2005; SOUSA, 2003).

A análise desse demonstrativo e das informações econômicas nele expostas possibilita redirecionar as ações estratégicas das empresas, uma vez que seu objetivo principal é remeter qualidade aos fenômenos decorrentes do incremento de valor adicionado, aos insumos da entidade em sua atividade operacional, enaltecendo o papel e a parcela de contribuição da organização ao meio social.

Como pode ser embasado por Santos (1999, p. 98): "a Demonstração de Valor Adicionado [...] deve ser entendida como a forma mais competente criada pela contabilidade para auxiliar na medição e demonstração da capacidade de geração, bem como de distribuição, da riqueza de uma entidade”. Sob essa ótica e remetida ao cenário econômico, a DVA constitui base para composição do Produto Interno Bruto (PIB) de forma que sua adequada mensuração pode auxiliar a economia no cálculo de agregados macroeconômicos.

A Demonstração do Valor Adicionado (DVA) é segmentada de acordo com a geração e evidenciação da riqueza gerada pelas entidades em determinado período e subsequente distribuição, tem cunho social e permite análise do ponto de vista gerencial e social das movimentações.

No quadro 1 esta representado a estrutura da DVA exemplificando como se compõem o valor adicionado e de que maneira o valor adicionado é distribuído. 


\section{Quadro 1 - Estrutura da Demonstração do Valor Adicionado (DVA)}

\section{1) RECEITAS}

1.1) Vendas de mercadorias, produtos e serviços

1.2) Outras receitas

1.3) Receitas relativas à construção de ativos próprios

1.4) Provisão para créditos de liquidação duvidosa

2) INSUMOS ADQUIRIDOS DE TERCEIROS

2.1) Custos dos produtos, das mercadorias e dos serviços vendidos

2.2) Materiais, energia, serviços de terceiros e outros

2.3) Perda / Recuperação de valores ativos

2.4) Outras (especificar)

3) VALOR ADICIONADO BRUTO (1-2)

4) DEPRECIAÇÃO, AMORTIZAÇÃO E EXAUSTÃO

5) VALOR ADICIONADO LÍQUIDO PRODUZIDO PELA ENTIDADE (3-4)

6) VALOR ADICIONADO RECEBIDO EM TRANSFERÊNCIA

6.1) Resultado de equivalência patrimonial

6.2) Receitas financeiras

6.3) Outras

7) VALOR ADICIONADO TOTAL A DISTRIBUIR (5+6)

8) DISTRIBUIÇÃO DO VALOR ADICIONADO $(*)$

\section{1) Pessoal}

8.1.1 - Remuneração direta

8.1.2 - Benefícios

8.1.3 - F.G.T.S

8.2) Impostos, taxas e contribuições

8.2.1 - Federais

8.2.2 - Estaduais

8.2.3 - Municipais

\section{3) Remuneração de capitais de terceiros}

8.3.1 - Juros

8.3.2- Aluguéis

8.3.3 - Outras

8.4) Remuneração de Capitais Próprios

8.4.1 - Juros sobre o Capital Próprio

8.4.2 - Dividendos

8.4.3 - Lucros retidos / Prejuízo do exercício

8.4.4 - Participação dos não-controladores nos lucros retidos

Fonte: adaptado de Comitê dos Pronunciamentos Contábeis (2008).

As demonstrações contábeis obrigatórias bem como o período e a frequência de apresentações são estabelecidas pela legislação vigente e são postas de acordo com a constituição das entidades. 


\subsection{VALOR ADICIONADO}

O valor adicionado tem conceitos completamente diferentes mediante a visão econômica e contábil. Na visão contábil, o valor adicionado é representado pela diferença entre o valor das vendas e os insumos pagos a terceiros, já na visão econômica, significa o quanto de riqueza a empresa pode agregar aos insumos de sua produção.

Para Simonsen e Cysne (1999), "denomina-se valor adicionado em determinada etapa de produção a diferença entre o valor bruto produzido nesta etapa (igual à venda mais acréscimo de estoques) e os consumos intermediários".

Denomina-se valor adicionado em determinada etapa de produção, a diferença entre o valor bruto da produção e os consumos intermediários nessa etapa. Assim, o produto nacional pode ser concebido como "a soma dos valores adicionados, em determinado período de tempo, em todas as etapas dos processos de produção do país" (SIMONSEN apud SANTOS, 2007, p. 27).

Valor adicionado representa a riqueza criada pela empresa, de forma geral medida pela diferença entre o valor das vendas e os insumos adquiridos de terceiros. Inclui também o valor adicionado recebido em transferência, ou seja, produzido por terceiros e transferido à entidade. (CPC 09, 2008, p. 3)

Desse modo, destaca-se a importância do processo produtivo no país como uma atividade social que busca conciliar recursos com a criação de bens e serviços satisfazendo as necessidades humanas.

Um dos indicadores que avalia o desempenho de um país, aliada a sua capacidade produtiva, mediante ao total de mercadorias e serviços produzidos em um determinado período pelo comércio, indústria e agricultura, é o Produto Interno Bruto (PIB).

É importante destacar que o valor adicionado corresponde ao valor que em cada etapa da produção foi adicionado ao valor das matérias-primas utilizadas. Desta forma, visualiza-se que o PIB pode ser mensurado de duas formas: pela agregação dos valores adicionados em cada etapa da produção ou pelo valor dos bens finais.

\subsection{GERAÇÃO DA RIQUEZA E DISTRIBUIÇÃO DO VALOR ADICIONADO}

A Demonstração do Valor Adicionado é divida em duas partes, sendo que a primeira retrata a geração da riqueza e a segunda apresenta de que forma a riqueza foi distribuída entre os principais agentes econômicos da entidade. São eles: pessoal; impostas, taxas e contribuições; remuneração de capitais de terceiros e remuneração de capitais próprios. conceitos:

$\mathrm{Na}$ geração de riquezas, relacionados na primeira parte da DVA, tem-se os seguintes

a) Receitas: inclui venda de mercadorias, produtos e serviços; outras receitas e provisão para créditos de liquidação duvidosa, incluindo os valores relativos à constituição desta provisão. Nos dois primeiros itens, inclui os tributos incidentes sobre as receitas.

b) Insumos adquiridos de terceiros: neste item inclui valores das matérias-primas adquiridas de terceiros, contidas no custo dos produtos, das mercadorias e dos serviços prestados. Também devem constar valores relativos às despesas originadas da utilização de materiais, energia e serviços de terceiros. Além disso, deve-se agregar neste item depreciação, amortização e exaustão, além de perda e recuperação de valores ativos.

c) Valor Adicionado Bruto: resultante da diferença entre o valor das receitas e o valor dos insumos consumidos para a geração destas receitas.

d) Depreciação, amortização e exaustão: inclui a despesa ou o custo contabilizado no período.

Revista Ambiente Contábil - ISSN 2176-9036 - UFRN - Natal-RN. v. 10. n. 1, p. 200 - 222, jan./jun. 2018. 
e) Valor Adicionado Líquido: valor agregado pela empresa ao produto ou serviço vendido, já descontados os consumos intermediários e a depreciação.

f) Valor Adicionado recebido em transferência: neste item inclui o resultado da equivalência patrimonial; receitas financeiras, como juros e descontos, além de variações cambiais ativas e, outras receitas, como aluguéis, direitos de franquias, dentre outros.

g) Valor Adicionado: riqueza gerada durante o período. Representa o valor adicionado a distribuir.

Na segunda parte da DVA tem-se de forma detalhada como a riqueza obtida foi distribuída pela empresa.

a) Pessoal: neste item inclui-se remuneração direta dos trabalhadores, como: salários, $13^{\circ}$ salário, férias, comissões, horas extras, honorários da administração, participação nos resultados, dentre outros. Além de benefícios, como assistência médica, alimentação e transporte, bem como o FGTS.

b) Impostos, taxas e contribuições: neste item são incluídos os impostos da esfera municipal, estadual e federal, dentre os quais, destacam-se: ICMS, IPI, ISS, II, IPTU, IOF, IRPJ, CSLL, PIS e COFINS. Além destes, alguns autores incluem as contribuições que as empresas fazem ao INSS, por entenderem que as mesmas têm mais características de tributo do que remuneração indireta ao empregado.

c) Remuneração de capitais de terceiros: inclui-se neste item valores pagos pela remuneração do capital investido na empresa sob a forma de empréstimo e financiamentos.

d) Remuneração de capitais próprios: recebem parte do valor adicionado pela remuneração atribuída a sócios e acionistas. Esta remuneração é realizada de várias formas, das quais destacamos: juros sobre capital próprio e dividendos, lucros retidos e absorção do valor adicionado negativo. Inclui-se neste item a participação dos acionistas minoritários.

\subsection{ESTUDOS ANTERIORES}

Cunha (2005) destaca que: [...] Além de atender a um maior número de usuários, quando comparada à DRE, amplia o universo atingido pela contabilidade e tem a grande vantagem de ser facilmente lida e interpretada. Como mostrado, serve como um excelente instrumento de análise, principalmente quando a questão é comparativa. Por meio da DVA, consegue-se perceber como a riqueza criada foi distribuída aos agentes e quais deles ficaram com a maior parte dela, possibilitando, inclusive, avaliações sobre se esses são os agentes que mais colaboraram na sua criação. É o caso do governo, que sempre fica com parte substancial da riqueza gerada.

Silva e Marques (2015) comentam que em relação ao valor adicionado, notou-se como essa informação é útil para efeitos da mensuração do PIB, fornecendo dados relevantes que podem servir de base para calcular o Produto Interno Bruto, haja vista que o somatório dos valores adicionados das unidades produtivas já determina o próprio PIB. A DVA pode servir de instrumento para melhor pôr-se em prática os princípios constitucionais da capacidade contributiva, da justiça tributária e mesmo para melhor formular e avaliar as políticas tributárias.

Pegoraro et al. (2010, p. 9) enfatiza que: [...] o quão interessante é a análise das informações contidas neste relatório, para as pessoas e as organizações, que possuam alguma relação com a empresa, para que se obtenham informações da participação na distribuição do valor agregado como subsídio para futuras decisões. O estudo mostrou ainda, a vantagem que esse demonstrativo possui em ser facilmente elaborado a partir de informações emanadas da própria contabilidade da companhia, tornando-o de fácil compreensão. Assim a DVA pode ser considerada como um excelente instrumento macroeconômico e de mensuração da riqueza gerada pelas atividades empresariais.

Revista Ambiente Contábil - ISSN 2176-9036 - UFRN - Natal-RN. v. 10. n. 1, p. 200 - 222, jan./jun. 2018. 


\section{PROCEDIMENTOS METODOLÓGICOS}

Para o desenvolvimento deste artigo, utilizou-se a abordagem quantitativa e qualitativa da pesquisa, e quanto aos objetivos, utilizou-se a pesquisa exploratória descritiva.

Segundo Gerhardt e Silveira (2009, p. 34), a pesquisa segmentada sob essa ótica “objetiva gerar conhecimentos novos, úteis para o avanço da ciência, sem aplicação prática prevista. Envolve verdades e interesses universais".

Dessa forma, um estudo da demonstração do valor adicionado, com o intuito de verificar a evolução e a distribuição da riqueza das empresas catarinenses, de capital aberto, caracteriza-se por um estudo cujas conclusões derivam de uma pesquisa básica.

Atualmente o Estado de Santa Catarina está representado no mercado de futuros da BM\&FBOVESPA por 23 entidades de diversos ramos de atuação, população foco da pesquisa, como podem ser observados no quadro 2 abaixo:

Quadro 2 - Empresas catarinenses de capital aberto listadas na BM\&FBOVESPA conforme ramo de atividade

\begin{tabular}{|c|c|}
\hline Entidade & Ramo de Atividade \\
\hline BRF S.A. & Alimentício \\
\hline BUETTNER S.A. INDÚSTRIA E COMÉRCIO & Têxtil \\
\hline CENTRAIS ELET DE SANTA CATARINA S.A. & Utilidade Pública \\
\hline CIA CATARINENSE DE AGUAS E SANEAMENTO - CASAN & Utilidade Pública \\
\hline CIA DOCAS DE IMBITUBA & Construção e Transporte \\
\hline CIA HERING & Têxtil \\
\hline CIA INDUSTRIAL SCHLOSSER S.A. & Têxtil \\
\hline CREMER S.A. & Saúde e Medicamentos \\
\hline DOHLER S.A. & Têxtil \\
\hline ELECTRO ACO ALTONA S.A. & Máquinas e Equipamentos \\
\hline KARSTEN S.A. & Têxtil \\
\hline LOJAS HERING S.A. & Comércio \\
\hline METALURGICA RIOSULENSE S.A. & Metalúrgico \\
\hline METISA METALURGICA TIMBOENSE S.A. & Metalúrgico \\
\hline PBG S/A & Construção e Transportes \\
\hline POMIFRUTAS S/A & Alimentício \\
\hline SCHULZ S.A. & Máquinas e Equipamentos \\
\hline STATKRAFT ENERGIAS RENOVAVEIS S.A. & Utilidade Pública \\
\hline TEKA-TECELAGEM KUEHNRICH S.A. & Têxtil \\
\hline TEXTIL RENAUXVIEW S.A. & Têxtil \\
\hline TRACTEBEL ENERGIA S.A. & Utilidade Pública \\
\hline TUPY S.A. & Materiais de Transporte \\
\hline WEG S.A. & Máquinas e Equipamentos \\
\hline
\end{tabular}

Fonte: elaborado pelos autores.

Primeiramente, a análise efetuada foi construída de forma global, compilando todas as informações em uma única base, tendo-se então os quocientes das 23 empresas em análise do referido estudo.

Posteriormente, as empresas foram divididas por ramo de atividade. Os ramos são indústria, onde foram enquadradas 17 das 23 empresas analisadas, comércio, 1 entidade e serviços, 5 entidades.

Com base na análise das atividades das entidades que comercializam suas ações cerca de $35 \%$, estão direcionadas a produção e comercialização de tecidos, vestuário e calçados; aproximadamente $18 \%$ direcionam suas atividades principais, a produção e comercialização

Revista Ambiente Contábil - ISSN 2176-9036 - UFRN - Natal-RN. v. 10. n. 1, p. 200 - 222, jan./jun. 2018. 
de máquinas e equipamentos, $18 \%$ são prestadoras de serviços de utilidade pública como energia elétrica, água e saneamento. Do total, somente nove por cento das entidades atuam no setor alimentício, de materiais de transportes, na construção, e 4\% na área de saúde e medicamentos.

Estas ainda foram segregadas por segmento de atuação, totalizando 09 setores, sendo: utilidade pública (4); serviços de transporte (1); alimentos (2); têxtil (7); construção e transportes (1); saúde e medicamentos (1); máquinas e equipamentos (3); metalurgia (2); material de transporte (1) e (1) setor varejista.

A análise se deu de forma global, por ramo de atividade e segmento de atuação. A segregação das empresas procedeu à análise da distribuição do valor adicionado, tomando como base a distribuição entre itens sugerida pelos modelos contidos no Pronunciamento Técnico $\mathrm{n}^{\circ} 09$ do Comitê de Pronunciamentos, via as quatro vertentes de análise: pessoa; impostos, taxas e contribuições; remuneração de capitais de terceiros e remuneração de capitais próprios.

Desta forma, verificou-se, de forma geral, por ramo de atividade e segmento, o quociente de distribuição de riqueza para cada uma das vertentes da DVA. A coleta de dados se deu através das informações das DVA Consolidadas de cada uma das empresas, extraídas diretamente no site da BM\&F BOVESPA ou, quando não disponíveis no mesmo, no site das próprias empresas.

As informações referentes ao valor adicionado no PIB foram retiradas do site do Estado de Santa Catarina e confrontadas com o valor adicionado gerado por todas as empresas. Ainda, quanto à análise das despesas com pessoal e com empregados, a quantidade de funcionários foi retirada do Formulário de Referência de cada uma das empresas e confrontada com o total da distribuição de despesas com pessoal.

A abordagem do estudo se deu em um primeiro momento, com a coleta de informações através da análise das demonstrações contábeis, notas explicativas e formulário de referência, de modo qualitativo. Nesse método de pesquisa existe, sob a ótica de Trivinos (1987, p. 118): "Um tipo de objetividade e de validade conceitual, [...], que contribuem decisivamente para o desenvolvimento do pensamento científico".

Ainda segundo o autor "a pesquisa qualitativa tem suas raízes nas práticas desenvolvidas pelos antropólogos, primeiro e, em seguida, pelos sociólogos em seus estudos sobre a vida em comunidades". A afirmação remete ao objetivo geral do estudo, que é o de analisar a distribuição e a evolução da riqueza das empresas catarinenses de capital aberto listadas na BM\&FBOVESPA nos anos 2010 a 2015 através da DVA. Para possibilitar tal análise serão utilizados os indicadores elaborados por Iudícibus et al. (2010), conforme quadro 3 abaixo:

Quadro 3 - Indicadores para análise da DVA

\begin{tabular}{|c|c|c|c|}
\hline \multicolumn{3}{|c|}{ Distribuição de Riqueza } \\
\hline $\begin{array}{c}\text { Quociente entre gastos } \\
\text { com pessoal e valor } \\
\text { adicionado }\end{array}$ & $\begin{array}{c}\text { Quociente entre gastos } \\
\text { com impostos e valor } \\
\text { adicionado }\end{array}$ & $\begin{array}{c}\text { Quociente entre gastos } \\
\text { com remuneração de } \\
\text { capital de terceiros e valor } \\
\text { adicionado }\end{array}$ & $\begin{array}{c}\text { Quociente entre gastos } \\
\text { com remuneração de } \\
\text { capital próprio e valor } \\
\text { adicionado }\end{array}$ \\
\hline
\end{tabular}

Fonte: adaptado de Iudícibus et al. (2010).

Para possibilitar a análise da evolução da distribuição da riqueza produzida pelas empresas de capital aberto da amostra, foi utilizado o cálculo com base nestes quatro indicadores (para cada empresa pertencente da amostra da pesquisa). $\mathrm{O}$ estudo se justifica ao 
analisar o impacto causado pela célula social e, consequentemente tornar a informação útil aos usuários em todos os níveis bem como meios para análise, além de representar um método eficaz de crescimento e de continuidade das entidades.

Em um segundo momento quando as ações forem relativas à tabulação de dados e formulação de resultados o estudo se dará de modo quantitativo, segundo Fonseca (2002, p. 20):

[...] A pesquisa quantitativa recorre à linguagem matemática para descrever as causas deum fenômeno, as relações entre variáveis, etc. A utilização conjunta da pesquisa qualitativa e quantitativa permite recolher mais informações do que se poderia conseguir isoladamente.

A cerca da finalidade do estudo decorrente da pesquisa, essa é descritiva, tendo por objetivo estudar as características de um grupo e os procedimentos utilizados para verificar as associações entre variáveis desse determinado grupo (GIL, 1991). Para apoiar o problema de pesquisa do estudo, afirma sob este método, o autor Trivinos (1987, p. 110), "O estudo descritivo pretende "descrever" com exatidão os fatos e fenômenos de determinada realidade".

No que tange os procedimentos a ser utilizados para o alcance dos objetivos emanados do estudo, o método utilizado será por meio documental, como abordado por Gil (1991, p. 29):

\footnotetext{
A pesquisa documental apresenta uma série de vantagens. Primeiramente há que se considerar que os documentos constituem fonte rica e estável de dados. Como os documentos subsistem ao longo do tempo, tornam-se a mais importante fonte de dados em qualquer pesquisa de natureza histórica.
}

A partir da análise dos dados das Demonstrações do Valor Adicionado, estabelecidos os parâmetros, é objetivo do estudo determinar quais são as destinações e qual a sua composição de acordo com a atividade e do impacto no resultado da empresa.

\section{RESULTADOS E DISCUSSÕES}

Pelo presente estudo, mediante análise do Demonstrativo do Valor Adicionado (DVA), no período de seis anos, de 2010 a 2015, analisou-se 23 empresas catarinenses, listadas na BM\&FBOVESPA. As mesmas foram agrupadas de forma global, por ramo de atividade e por setor. Cabe ressaltar que o trabalho pode ter algum viés, devido à amostra ser diversificada, e em alguns casos, apresentar dados diferentes.

\subsection{ANÁLISE GLOBAL}

No que se refere ao estudo, por ramo de atividade, foram analisadas 5 empresas prestadoras de serviço, representando $21,74 \%$ do total da amostra, 17 empresas industriais, sendo $73,91 \%$, e 1 empresa comercial, ou $4,35 \%$.

Segundo o segmento das empresas prestadoras de serviço, as mesmas foram divididas entre os setores de serviços públicos (4) e serviços de transporte (1). As empresas industriais foram distribuídas entre os setores de: alimentos (2); têxtil (7); construção e transportes (1); saúde e medicamentos (1); máquinas e equipamentos (3); metalurgia (2) e material de transporte (1). Das empresas comerciais uma (1) pertence ao setor varejista.

O montante do valor adicionado referente as 23 empresas do referido estudo expresso em moeda corrente do ano de 2010 a 2015, foi de 20,9 bilhões de reais para 37,5 bilhões, respectivamente. Um acréscimo de 79,27\% no valor adicionado entre os períodos analisados. 
Conforme tabela 1, verificamos a representatividade em percentual do valor adicionado no PIB do Estado de Santa Catarina.

Tabela 1 - Participação do valor adicionado no PIB de SC de 2010 a 2014 das empresas catarinenses listadas na BM\&FBOVESPA

\begin{tabular}{lccccc}
\hline \% Participação do V.A no PIB de SC & $\mathbf{2 0 1 4}$ & $\mathbf{2 0 1 3}$ & $\mathbf{2 0 1 2}$ & $\mathbf{2 0 1 1}$ & $\mathbf{2 0 1 0}$ \\
\hline PIB do Estado de Santa Catarina $(*)$ & 233,8 & 214,2 & 177,3 & 169,0 & 152,5 \\
Valor Adicionado Gerado $(*)$ & 29,9 & 25,5 & 24,4 & 24,0 & 20,9 \\
\% Participação do V.A no PIB & $12,77 \%$ & $11,91 \%$ & $13,74 \%$ & $14,21 \%$ & $13,72 \%$ \\
\hline
\end{tabular}

(*) Valor Adicionado e do PIB em bilhões de reais.

Fonte: os autores.

O Produto Interno Bruto (PIB) do Estado de Santa Catarina vem em uma crescente, ao tempo que o valor adicionado gerado pelas empresas catarinenses deste estudo também, quando se tem por análise o valor. Porém, analisando-se percentualmente, percebe-se uma queda de 2010 para 2014. A variável de participação do valor adicionado em relação ao PIB catarinense oscilou positivamente em 2010 (13,72\%) e em 2011 (14,21\%). Nos períodos de 2012 a 2015 a oscilação foi decrescente. A análise do ano de 2015 não foi realizada pelo fato do PIB do referido ano não estar divulgado.

Neste sentido, ao analisar-se os dados dos demonstrativos do valor adicionado, demonstrados de forma global a distribuição da riqueza gerada em quatro vertentes: pessoal e empregados; impostos, taxas e contribuições (governo); remuneração de capitais de terceiros e remuneração de capitais próprios, conforme apresentamos na tabela 2.

Tabela 2 - Distribuição do valor adicionado em \% de 2010 a 2015 das empresas catarinenses listadas na BM\&FBOVESPA

\begin{tabular}{lcccccc}
\hline Distribuição do Valor Adicionado & $\mathbf{2 0 1 5}$ & $\mathbf{2 0 1 4}$ & $\mathbf{2 0 1 3}$ & $\mathbf{2 0 1 2}$ & $\mathbf{2 0 1 1}$ & $\mathbf{2 0 1 0}$ \\
\hline Pessoal & 51,04 & 38,21 & 39,50 & 40,34 & 30,69 & 48,06 \\
Impostos, taxas e contribuições & 22,38 & 22,52 & 26,69 & 0,99 & 28,51 & 33,18 \\
Remuneração de capitais de terceiros & 47,18 & 29,09 & 21,57 & $(40,05)$ & 19,07 & 36,33 \\
Remuneração de capitais próprios & $(20,60)$ & 10,17 & 12,24 & 98,72 & 17,38 & $(21,92)$ \\
\hline
\end{tabular}

Fonte: elaborada pelos autores.

A distribuição do valor adicionado entre as 4 vertentes de análise deve ser de $100 \%$. Em algum momento os dados estão apresentados negativos, pois a distribuição do valor adicionado foi negativa, e quando não foi, o dado apresentado negativo foi relevante: na remuneração de capitais de terceiros e nos lucros ou prejuízos apresentados, impactados por empresas do ramo têxtil nos referidos anos em análise.

Deste modo, observou-se que de 2010 a 2015, a distribuição do valor adicionado tem destaque mantendo-se em primeiro lugar na distribuição da riqueza criada para o pessoal e empregados, com uma média percentual variando de 30,69\% ao máximo de 51,04\%. O único ano em que a distribuição para pessoal e empregados não se manteve em primeiro lugar, foi em 2012. Neste ano, a remuneração de capitais próprios atingiu 98,72\%, valores superiores destinados aos financiadores do capital interno, em forma de dividendos e juros sobre capital próprio.

No mesmo período em análise, porém nos anos de 2010, 2014 e 2015, a remuneração de capitais de terceiros esteve na segunda posição. Impactados principalmente pelos juros e aluguéis, destinados a financiadores externos. Observa-se que nos anos de 2011 e 2013, o recolhimento destinado ao governo através de impostos, taxas e contribuições ocupou a segunda colocação. Porém, tal panorama se modifica e passa a ocupar a terceira colocação, nos anos de 2010, 2014 e 2015, em relação à distribuição da riqueza destinada ao governo.

Revista Ambiente Contábil - ISSN 2176-9036 - UFRN - Natal-RN. v. 10. n. 1, p. 200 - 222, jan./jun. 2018. 
A remuneração de capitais próprios ocupa a última colocação, nos anos de 2010 e 2011, e de 2013 a 2015. Destaque para a riqueza não distribuída nos anos de 2010 e 2015, o percentual foi impactado pelo desempenho principalmente das empresas do ramo têxtil e alimentício. Ainda, no que diz respeito à distribuição da riqueza para empregados, buscamos os dados referentes à quantidade de funcionários através do formulário de referência publicado na BM\&FBOVESPA de cada empresa. O número de empregados por empresa, esta demonstrado no gráfico 1 .

\section{Gráfico 1 - Número total de empregados de 2010 a 2015}

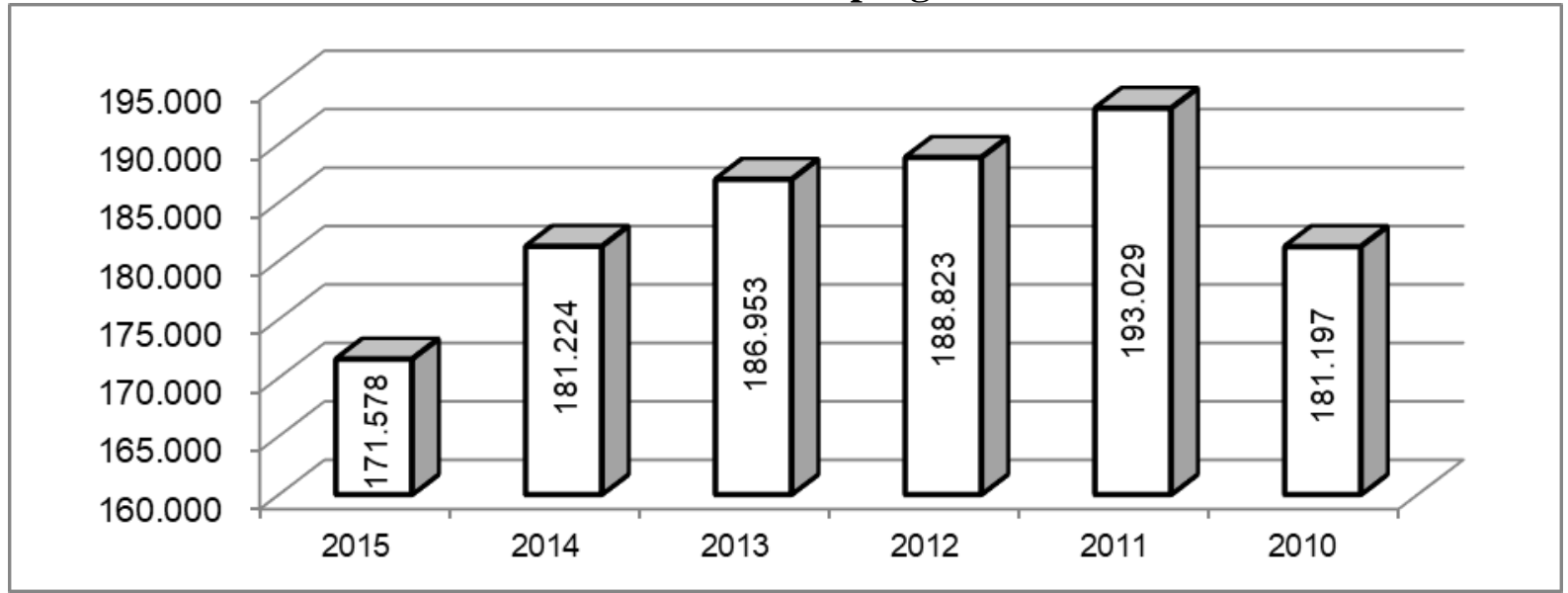

Fonte: elaborada pelos autores.

No período em análise, de 2010 a 2015, verificou-se que a quantidade de funcionários teve uma decrescente de 5,31\%, chegando a seu maior pico no ano de 2011. Desta forma, ainda buscamos analisar o valor agregado distribuído a cada funcionário. Obtemos essa informação dividindo-se o valor distribuído para pessoal e empregados, na forma de remuneração direta, benefícios, FGTS e outros, pela quantidade de empregados no ano, representado no gráfico 2 .

\section{Gráfico 2 - Despesas com pessoal por empregado de 2010 a 2015 em mil}

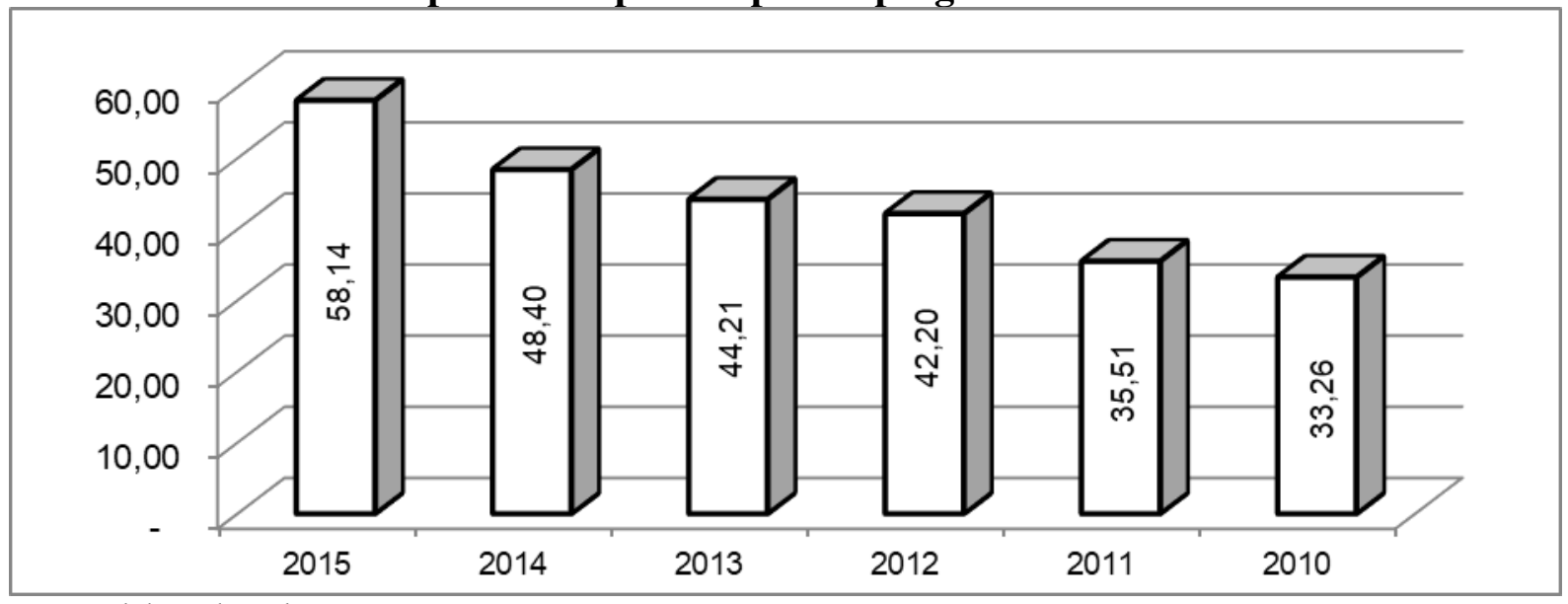

Fonte: elaborado pelos autores.

Percebe-se que, que durante o período de análise o valor de despesas com pessoal seguiu crescente durante os 6 anos, tendo variado de $\mathrm{R} \$ 33,26$ a $\mathrm{R} \$ 58,14$ mil reais, representando um acréscimo de $74,78 \%$. Reduziu-se a quantidade de empregados, mas aumentou a remuneração. Esse fenômeno é explicado devido ao aumento de remuneração 
direta com indenizações trabalhistas, principalmente, em empresas do ramo alimentício e metalúrgico.

\subsection{ANÁLISE POR RAMO DE ATIVIDADE}

É parte do método utilizado por este estudo promover a comparação de dados entre os ramos dos quais as entidades que compõe a amostra fazem parte. Os ramos são indústria, onde foram enquadradas 17 das 23 empresas analisadas; comércio, uma entidade e serviços, 5 entidades.

$\mathrm{Na}$ sequência, conforme tabela 3, podem-se observar as informações gerais da indústria, entre 2010 e 2015 das empresas catarinenses listadas na BM\&FBOVESPA.

Tabela 3 - Informações gerais do valor adicionado no ramo da indústria entre 2010 a 2015

\begin{tabular}{lcccccc}
\hline INDÚSTRIA & $\mathbf{2 0 1 5}$ & $\mathbf{2 0 1 4}$ & $\mathbf{2 0 1 3}$ & $\mathbf{2 0 1 2}$ & $\mathbf{2 0 1 1}$ & $\mathbf{2 0 1 0}$ \\
\hline Pessoal & 64,18 & 45,77 & 47,34 & 48,02 & 36,07 & 58,04 \\
Impostos, taxas e contribuições & 19,52 & 21,44 & 25,93 & $(10,02)$ & 28,19 & 35,35 \\
Remuneração de capitais de terceiros & 58,07 & 32,04 & 23,53 & $(61,60)$ & 20,76 & 40,54 \\
Remuneração de capitais próprios & $(41,77)$ & 0,75 & 3,20 & 123,60 & 9,10 & $(33,93)$ \\
\hline Receita (*) & 57.848 & 51.979 & 52.302 & 48.077 & 42.955 & 37.610 \\
Valor Adicionado Gerado (*) & 26.294 & 21.575 & 18.380 & 17.205 & 16.436 & 14.378 \\
Participação do \% V A na Receita & $45,45 \%$ & $41,51 \%$ & $35,14 \%$ & $35,79 \%$ & $38,26 \%$ & $38,23 \%$ \\
Quantidade total de empregados & 164.429 & 174.217 & 180.355 & 181.801 & 185.905 & 174.236 \\
Despesa com pessoal $(*)$ & 8.832 & 7.740 & 7.255 & 6.794 & 5.973 & 5.219 \\
\hline
\end{tabular}

(*) Receita, valor adicionado gerado e despesa com pessoal em bilhões de reais.

Fonte: os autores.

A indústria é o ramo que detém o maior valor adicionado e a maior receita gerada durante todo o período em análise. Observa-se que há uma evolução crescente nestas variáveis. Pela observação da tabela 3 , pode-se constatar que a riqueza criada durante o período analisado oscilou positivamente, sendo um incremento de $82,87 \%$ quando se compara 2010 e 2015. A receita também cresceu no período, sendo esta de 53,81\%. Esse crescimento pode ser explicado em parte pela diversidade do ramo (agropecuário, e de transformação) e extensão do parque fabril, bem como este crescimento pode ser alavancado por meio de incentivos através de políticas governamentais e oscilações positivas do mercado internacional.

A comparação entre todas as empresas do ramo industrial, como se pode perceber, sofreu variações das médias anuais denotando a maior distribuição de valor para gastos com pessoal, variações entre $36,07 \%$ a $64,18 \%$ do total a ser distribuído. A indústria é o ramo que mais empregou neste período, porém percebe-se uma queda constante na empregabilidade na indústria de 2011 a 2015. O contingente analisado no ramo industrial representa $96 \%$ da amostra. O decréscimo em empregabilidade no período analisado foi de 5,63\%, resultado do momento instável da economia brasileira que obriga o segundo setor a rever despesas de aspecto social, de modo que as entidades buscam automatizar e atualizar mecanismos de produção de modo geral, contribuindo para a redução dos percentuais de distribuição de riquezas para com este quociente.

A segunda maior distribuição está vinculada a remuneração de capitais de terceiros, partindo de $-61,60 \%$ a 58,07\%, atrelada a esse fato está à remuneração de capitais próprios, oscilando para maior ou menor distribuição de acordo com o valor pago a título de juros, aluguéis e outros do mesmo período. O terceiro quociente de distribuição para o qual houve 
mais destinações foram impostos, taxas e contribuições, com índices que variam de $-10,02 \%$ em 2012 a 35,35\% em 2010 do total de valores adicionados a serem distribuídos.

$\mathrm{Na}$ sequência, conforme tabela 4, é possível observar as informações gerais do comércio, entre 2010 e 2015 das empresas catarinenses listadas na BM\&FBOVESPA.

Tabela 4 - Informações gerais do valor adicionado no ramo do comércio entre 2010 a 2015

\begin{tabular}{lcccccc}
\hline COMÉRCIO & $\mathbf{2 0 1 5}$ & $\mathbf{2 0 1 4}$ & $\mathbf{2 0 1 3}$ & $\mathbf{2 0 1 2}$ & $\mathbf{2 0 1 1}$ & $\mathbf{2 0 1 0}$ \\
\hline Pessoal & 15,05 & 16,18 & 1,35 & 7,22 & 4,60 & 13,75 \\
Impostos, taxas e contribuições & 30,35 & 20,34 & 33,72 & 31,51 & 30,25 & 23,39 \\
Remuneração de capitais de terceiros & 35,11 & 36,72 & 3,24 & 18,79 & 13,00 & 57,14 \\
Remuneração de capitais próprios & 19,49 & 26,76 & 61,70 & 42,48 & 52,15 & 5,71 \\
\hline Receita (*) & 3,8 & 3,3 & 23,2 & 4,7 & 6,7 & 2,4 \\
Valor Adicionado Gerado (*) & 2,5 & 1,9 & 22,1 & 3,8 & 5,8 & 1,5 \\
Participação do \% V A na Receita & $64,31 \%$ & $58,28 \%$ & $95,21 \%$ & $80,15 \%$ & $86,63 \%$ & $63,99 \%$ \\
Quantidade total de empregados & 11 & 14 & 11 & 8 & 8 & 7 \\
Despesa com pessoal (**) & 0,370 & 0,315 & 0,297 & 0,273 & 0,265 & 0,207 \\
\hline
\end{tabular}

(*) Receita e valor adicionado gerado em milhões de reais.

$(* *)$ Despesa com pessoal em mil reais.

Fonte: elaborada pelos autores.

O comércio é o ramo de atividade que menos emprega com relação à amostra. Também é o menos contribui em relação a sua receita e a que menos criou riqueza no período em análise. Esta oscilação nos indicadores se deu pela relativa diminuição nas vendas no período de análise, resultado da crise econômica, que afetou a população diminuindo seu poder de compra em virtude do aumento do desemprego, da inadimplência e dos juros praticados. Outro fator determinante foi o corte de incentivos governamentais (fiscais e de linhas de crédito) que afetaram significativa e negativamente os preços praticados.

Porém, ainda assim os indicadores mostram a evolução tanto na receita quanto na distribuição da riqueza gerada mesmo que relativamente pequena, sendo de 62,50\% e 63,32\%, respectivamente. Ao que se refere à análise do ramo de comércio, representada nesta ocasião por apenas uma organização, das 23 entidades amostradas, de modo geral, a entidade remunera a índices superiores a $15 \%$ o capital investido, somente no primeiro ano de análise o índice ficou a baixo de $10 \%$.

Neste mesmo período a remuneração de capitais de terceiros alcançou índices que variam em 2013 de 3,24\% a 57,14\% em 2010. Como terceiro item mais representativo de distribuição, está os impostos que representam aproximadamente de 20,34\% a 33,72\% do total a ser distribuído. O item menos representativo é o de pessoal chegando ao mínimo de $1,35 \%$, como pode ser observado na tabela 4 . O comércio é o que menos emprega e em relação ao período possui uma queda na quantidade de empregados, sendo esta de $36,36 \%$.

Dando continuidade, conforme tabela 5, podem-se observar as informações gerais dos serviços, entre 2010 e 2015 das empresas catarinenses listadas na BM\&FBOVESPA. 
Tabela 5 - Informações gerais do valor adicionado no ramo da prestação de serviços entre 2010 a 2015

\begin{tabular}{lcccccc}
\hline SERVIÇO & $\mathbf{2 0 1 5}$ & $\mathbf{2 0 1 4}$ & $\mathbf{2 0 1 3}$ & $\mathbf{2 0 1 2}$ & $\mathbf{2 0 1 1}$ & $\mathbf{2 0 1 0}$ \\
\hline Pessoal & 13,55 & 16,93 & 20,46 & 20,84 & 17,62 & 21,01 \\
Impostos, taxas e contribuições & 30,50 & 26,62 & 27,86 & 32,31 & 29,23 & 27,74 \\
Remuneração de capitais de terceiros & 12,58 & 17,57 & 18,57 & 21,45 & 14,57 & 17,87 \\
Remuneração de capitais próprios & 43,37 & 38,88 & 33,10 & 25,40 & 38,58 & 13,37 \\
\hline Receita (*) & 21.219 & 16.852 & 14.283 & 13.582 & 12.525 & 11.826 \\
Valor Adicionado Gerado (*) & 11.217 & 8.278 & 7.112 & 7.156 & 7.581 & 6.546 \\
Participação do \% V A na Receita & $52,87 \%$ & $49,12 \%$ & $49,80 \%$ & $52,69 \%$ & $60,53 \%$ & $55,35 \%$ \\
Quantidade total de empregados & 7.138 & 6.993 & 6.587 & 7.014 & 7.116 & 6.954 \\
Despesa com pessoal $(*)$ & 1.143 & 1.031 & 1.010 & 1.174 & 880 & 808 \\
\hline
\end{tabular}

(*) Receita, valor adicionado gerado e despesa com pessoal em bilhões de reais.

Fonte: elaborada pelos autores.

O ramo de prestação de serviços é o segundo em receita e distribuição do valor adicionado gerado, quando falamos em valor. Percentualmente, é o ramo que mais cresceu nesses indicadores, sendo de 71,37\% no valor adicionado gerado e 79,42\% na receita.

Os índices encontrados através da tabulação de dados das entidades do ramo de serviços são derivados das Demonstrações de Valores Adicionados (DVA) de cinco entidades. Para esse ramo de atividade, exceto em 2010, o capital próprio investido foi o item mais representativo da distribuição de valores, chegando a 43,37\% em 2015. O segundo quociente para o qual se emanaram mais recursos foram os desembolsos relativos a gastos com impostos, taxa e contribuições, aproximadamente 30\%. A distribuição de valores com capitais de terceiros e pessoal, são respectivamente terceiro e quarto itens representativos como pode ser observado na tabela 5. O ramo de serviços é o que segundo mais emprega, sendo aproximadamente $4 \%$ em relação à amostra. Ao tempo do ramo industrial, a prestação de serviços também obteve um decrescimento em empregabilidade, porém menor, de 2,65\%.

Os resultados encontrados tanto para o aumento na geração de receita quanto para o aumento da empregabilidade são reflexo da economia de modo geral. Enquanto indústria e comércio buscam novas alternativas, dentre elas a diminuição de gastos trabalhistas, o setor de serviços é o último a ser impactado devido a sua indispensabilidade. Em sua maioria as empresas que compunham a amostra são de utilidade pública e sofrem forte influência do primeiro setor (através de políticas governamentais). Conforme demostrado pela análise, o cenário para este setor é crescimento para os próximos períodos.

\subsection{ANÁLISE POR SEGMENTO}

Em consonância com os objetivos propostos pelo estudo, através da tabela 6 pode-se observar o desempenho por segmento representado neste estudo de caso pelas 23 empresas da amostra. A amostra foi analisada segundo o segmento das empresas conforme tabela 6 , sendo que as mesmas foram divididas entre os setores: têxtil (7); comércio (1); alimentício (2); utilidade pública (4); construção e transportes (2); saúde e medicamentos (1); máquinas e equipamentos (3); metalurgia (2) e material de transporte (1). 
Ana Paula Günther Guesser, Juliana Fedrigo e André Carlos Einsweiller

Tabela 6 - Informações gerais do valor adicionado por segmento de atuação entre 2010 a 2015

\begin{tabular}{|c|c|c|c|c|c|c|}
\hline \multicolumn{7}{|c|}{ DISTRIBUIÇÃO DO VALOR ADICIONADO POR SEGMENTO } \\
\hline TÊXTIL & 2015 & 2014 & 2013 & 2012 & 2011 & 2010 \\
\hline Pessoal & 48,75 & 45,21 & 52,03 & 35,25 & 22,86 & 68,27 \\
\hline Impostos, taxas e contribuições & 14,89 & 21,12 & 28,24 & $(51,91)$ & 29,11 & 42,51 \\
\hline Remuneração capitais de terceiros & 73,45 & 44,96 & 30,42 & $(190,77)$ & 15,74 & 65,24 \\
\hline Remuneração capitais próprios & $(39,08)$ & $(11,30)$ & $(10,69)$ & 307,42 & 18,02 & $(76,03)$ \\
\hline COMÉRCIO & 2015 & 2014 & 2013 & 2012 & 2011 & 2010 \\
\hline Pessoal & 15,05 & 16,18 & 1,35 & 7,22 & 4,60 & 13,75 \\
\hline Impostos, taxas e contribuições & 30,35 & 20,34 & 33,72 & 31,51 & 30,25 & 23,39 \\
\hline Remuneração capitais de terceiros & 35,11 & 36,72 & 3,24 & 18,79 & 13,00 & 57,14 \\
\hline Remuneração capitais próprios & 19,49 & 26,76 & 61,70 & 42,48 & 52,15 & 5,71 \\
\hline ALIMENTÍCIO & 2015 & 2014 & 2013 & 2012 & 2011 & 2010 \\
\hline Pessoal & 198,35 & 65,85 & 58,53 & 106,09 & 81,17 & 108,95 \\
\hline Impostos, taxas e contribuições & 26,22 & 30,27 & 36,86 & 24,85 & 37,78 & 46,89 \\
\hline Remuneração capitais de terceiros & 133,46 & 50,26 & 36,40 & 70,82 & 60,64 & 68,54 \\
\hline Remuneração capitais próprios & $(208,02)$ & 3,63 & 18,21 & $(51,75)$ & $(29,58)$ & $(74,37)$ \\
\hline UTILIDADE PÚBLICA & 2015 & 2014 & 2013 & 2012 & 2011 & 2010 \\
\hline Pessoal & 21,25 & 21,16 & 23,92 & 26,05 & 22,02 & 26,27 \\
\hline Impostos, taxas e contribuições & 39,60 & 33,28 & 26,69 & 40,43 & 37,92 & 34,68 \\
\hline Remuneração capitais de terceiros & 35,43 & 30,08 & 26,59 & 28,87 & 23,88 & 22,33 \\
\hline Remuneração capitais próprios & 3,72 & 15,47 & $(2,20)$ & 4,66 & 16,18 & 16,72 \\
\hline CONSTRUÇÃO/TRANSPORTES & 2015 & 2014 & 2013 & 2012 & 2011 & 2010 \\
\hline Pessoal & 5,05 & 13,32 & 12,95 & 12,47 & 14,41 & 13,58 \\
\hline Impostos, taxas e contribuições & 15,90 & 20,99 & 21,35 & 23,52 & 21,66 & 21,98 \\
\hline Remuneração capitais de terceiros & $(25,30)$ & $(7,68)$ & $(4,29)$ & 2,64 & $(3,56)$ & 9,51 \\
\hline Remuneração capitais próprios & 104,35 & 73,37 & 69,99 & 61,36 & 67,49 & 4,93 \\
\hline SAÚDE E MEDICAMENTOS & 2015 & 2014 & 2013 & 2012 & 2011 & 2010 \\
\hline Pessoal & 33,30 & 37,17 & 41,27 & 84,32 & 41,48 & 41,52 \\
\hline Impostos, taxas e contribuições & 27,35 & 26,90 & 19,20 & $(23,52)$ & 22,26 & 24,10 \\
\hline Remuneração capitais de terceiros & 30,78 & 23,26 & 21,40 & 44,23 & 25,28 & 12,95 \\
\hline Remuneração capitais próprios & 8,56 & 12,67 & 18,13 & $(5,02)$ & 10,98 & 21,44 \\
\hline MÁQUINAS E EQUIPAMENTOS & 2015 & 2014 & 2013 & 2012 & 2011 & 2010 \\
\hline Pessoal & 48,38 & 49,22 & 45,51 & 43,73 & 41,38 & 41,28 \\
\hline Impostos, taxas e contribuições & 15,95 & 20,81 & 23,64 & 25,66 & 27,66 & 30,87 \\
\hline Remuneração capitais de terceiros & 24,52 & 15,71 & 15,72 & 16,74 & 16,22 & 12,83 \\
\hline Remuneração capitais próprios & 11,15 & 14,26 & 15,13 & 13,86 & 14,75 & 15,02 \\
\hline METALÚRGICO & 2015 & 2014 & 2013 & 2012 & 2011 & 2010 \\
\hline Pessoal & 55,70 & 39,90 & 46,35 & 46,68 & 41,42 & 40,63 \\
\hline Impostos, taxas e contribuições & 36,69 & 22,55 & 30,64 & 31,90 & 29,92 & 33,26 \\
\hline Remuneração capitais de terceiros & 42,12 & 26,07 & 15,56 & 20,11 & 20,18 & 18,28 \\
\hline Remuneração capitais próprios & $(34,52)$ & 11,48 & 7,45 & 1,31 & 8,49 & 7,83 \\
\hline MATERIAIS DE TRANSPORTE & 2015 & 2014 & 2013 & 2012 & 2011 & 2010 \\
\hline Pessoal & 65,21 & 70,59 & 65,96 & 63,01 & 48,43 & 51,62 \\
\hline Impostos, taxas e contribuições & 8,62 & 8,64 & 7,97 & 13,34 & 22,17 & 21,06 \\
\hline Remuneração capitais de terceiros & 8,21 & 12,09 & 17,77 & 16,50 & 7,42 & 6,35 \\
\hline Remuneração capitais próprios & 17,96 & 8,68 & 8,30 & 7,15 & 21,98 & 20,97 \\
\hline
\end{tabular}

Fonte: elaborada pelos autores.

Revista Ambiente Contábil - ISSN 2176-9036 - UFRN - Natal-RN. v. 10. n. 1, p. 200 - 222, jan./jun. 2018. 
Com relação ao segmente têxtil, o quociente relevante da distribuição evidenciado na tabela 6 é a remuneração de capitais de terceiros, que em 2010 e 2015 atingiram níveis expressivos em relação às demais vertentes da distribuição, no mesmo período, chegando a representar aproximadamente $70 \%$ do total da distribuição. Quanto ao quesito de distribuição para pessoal nos anos de 2010 e 2013, esses representavam respectivamente $68,27 \%$ e 52,03\% do total dos valores distribuídos, seu menor desempenho se deu em 2011 onde este representava apenas $22,86 \%$ da distribuição do valor adicionado pelas companhias no período. No que diz respeito ao recolhimento de impostos taxas e contribuições, o segmento têxtil apresenta queda no recolhimento, de impostos, taxas e contribuições. A remuneração de capitais próprios, segundo informações contidas nas demonstrações de valores adicionados das entidades com exceção de 2011 e 2012, deixou de existir

Quanto ao segmente comércio, a distribuição de valores evidenciada no quociente de remuneração de capitais próprios ocupa a primeira colocação na distribuição nos anos de 2011, 2012 e 2013. O indicador de remuneração de capital de terceiros em 2014 e 2015 é o segundo mais representativo com índices que variam de $36,72 \%$ a $35,10 \%$, respectivamente.

Os índices derivados das distribuições por pagamento de impostos, taxas e contribuições variam de 20,34\% em 2014 a 33,72\% em 2013 e, mantendo-se com pouca oscilação durante o período analisado tornando-se o terceiro item mais representativo. O item com menor índice de distribuição foram os relativos a gastos com pessoal que em 2013 eram 1,35\% do total distribuído e atingiu seu ápice de distribuição em 2014 com 16,18\%.

O setor alimentício é representado por duas empresas do grupo amostral, com base em seus demonstrativos ficou evidenciada a maior distribuição à retiradas para pagamentos de pessoal, em percentuais que superam os $100 \%$ nos anos de 2010, 2012, 2015 e com leves baixas nos períodos de 2013 e 2014. O segundo quociente que demandou mais distribuição foi à remuneração de capitais de terceiros, onde somente no período de 2013 o índice manteve-se abaixo dos $50 \%$, fato que acabou por prejudicar a distribuição de dividendos que inexistiu nos períodos em que a remuneração de capitais de terceiros ultrapassou $51 \%$. As distribuições destinadas à composição de taxas, impostos e contribuições nos anos de análise, apresentaram ligeiro declínio em todo período variando de $24,85 \%$ a 46,89\%.

No que tange a análise dos percentuais das empresas prestadoras de serviços de utilidade pública, os quocientes que se mostraram relevantes após a análise, são impostos, taxas e contribuições com variações de $26,69 \%$ a $40,43 \%$ e, remuneração de capitais de terceiros que variam de $22,33 \%$ a $35,43 \%$ do total distribuído no período. As despesas/custos com remuneração de pessoal foram responsáveis por variações entre $20 \%$ a $26 \%$ nos anos analisados. O percentual de 26,27\% no ano de 2010 é o mais elevado do período. Quando se trata da remuneração de capitais próprios os valores distribuídos foram decrescentes de 2010 a 2012 chegando a inexistir no ano de 2013.

Os percentuais evidenciados para o segmento de construção e transportes que foram representados por duas empresas da amostra tiveram seus índices impactados por dois fatores. Uma das entidades não apresentou resultados operacionais em suas demonstrações para o período de 2010, bem como vem acumulando prejuízos em todos os períodos analisados, chegando a ser excluída pela CVM da lista de empresas. Desta forma os percentuais mais significativos são os de remuneração de capitais próprios variando de 4,93\% em 2010 para $104,35 \%$ em 2015. Quanto aos impostos, taxa e contribuições tornou-se o segundo mais significativo, porém, exceto no período de 2012, que vem diminuindo. A distribuição relativa à pessoal é o terceiro item mais representativo e tem diminuído consideravelmente ao longo do período. A remuneração de capitais de terceiros tornou-se menos representativa nos últimos três períodos, apresentando saldo negativo de distribuição. 
O segmento de saúde e medicamentos é representado na BM\&FBOVESPA por apenas uma entidade no estado de Santa Catarina, essa organização destina grande parte do valor adicionado por ela produzido a gastos com pessoal variando de 33,30\% a 84,32\% em 2015 e 2012, respectivamente. A remuneração de capitais de terceiros apresentou-se como segundo quociente mais significativo em sua destinação, o que acaba por impactar os valores distribuídos aos sócios oscilando para mais, quando a remuneração de terceiros é baixa (em 2010 e 2013) e, para menos quando a oscilação de remuneração de terceiros é maior (em 2011, 2012, 2014 e 2015). Os índices de distribuição provenientes de impostos mantiveram-se entre $19,20 \%$ a $27,35 \%$ durante o período analisado.

Para este segmento de máquinas e equipamentos a principal vertente de distribuição está relacionada ao pessoal, onde os índices de distribuição variam de aproximadamente $41 \%$ a $49 \%$ do total a distribuir. Em segundo lugar somam-se as retiradas para pagamento de impostos, taxas e contribuições que sofreram um decréscimo ao longo do período analisado, porém, ainda representam significativos montantes. Em contraponto pode-se observar que os índices de remuneração de capitais de terceiros elevam-se em grande parte dos períodos e que acabam por relacionar-se com a destinação da remuneração de capitais próprios que em 4 dos 6 (2010 a 2013) períodos manteve-se abaixo dos $15 \%$.

Outro segmento avaliado pelo estudo é o metalúrgico, como resultado do estudo podese identificar que do total do valor adicionado a ser distribuído também teve o seu maior percentual destinado a gastos com pessoal variando de 39,90\% em 2014 a 55,70\% em 2015. Em sequência os valores destinados a pagamentos de taxa, impostos e contribuições ocupam a segunda maior destinação, porcentagens que variam de $22,55 \%$ a $36,69 \%$. Os valores distribuídos a título de remuneração de capitais de terceiros, ocupam a terceira posição no ranking de distribuição em 2013, ao passo que em 2015 nota-se a elevação dos índices, refletindo diretamente na distribuição da remuneração de capitais próprios.

O último segmento, parte da amostra deste estudo, trata setor de materiais de transporte, representado por uma entidade. A organização destinou valores que variam de 48,43 \% em 2011 até 70,59\% em 2014 do total de valores adicionados a desembolsos destinados a gastos com pessoal. A segunda maior destinação diz respeito a impostos, taxas e contribuições que oscilou de 7,97\% a 22,17\%. Como pode ser observado na tabela 6 os índices de remuneração de capitais próprios e de terceiros se intercalam denotando que em períodos de altos índices de financiamentos os resultados distribuíveis diminuem.

Diante dos dados analisados, empresas do ramo alimentício tendem a contribuir com a riqueza significativamente na vertente de remuneração de pessoal, impostos e remuneração de capitais de terceiros. No âmbito dos impostos e taxas, também contribuem com a distribuição de riqueza empresas do segmento metalúrgico, comércio e utilidade pública.

Quando verificado a remuneração de capitais de terceiros, empresas do ramo têxtil e metalúrgico são as que se destacam. Quanto à remuneração de capital próprio, empresas do ramo de construção e transportes são as que mais remuneram os sócios e acionistas.

\section{CONSIDERAÇÕES FINAIS}

A contabilidade em conjunto com as demonstrações contábeis tem se tornado ferramenta indispensável à adequada análise das possibilidades de manutenção e expansão das atividades operacionais das entidades que as utilizam.

$\mathrm{Na}$ análise da DVA, as empresas catarinenses foram segregadas de acordo com seu segmento de atuação. Após o período de análise cerca de 55\% da amostra distribuem os percentuais mais significativos de seus valores adicionados a gastos de origem trabalhista (pessoal). Cerca de $11 \%$ da amostra, representada por cinco entidades prestadoras de serviços de utilidade pública, destinam a, impostos taxas e contribuições a maior parte do valor

Revista Ambiente Contábil - ISSN 2176-9036 - UFRN - Natal-RN. v. 10. n. 1, p. 200 - 222, jan./jun. 2018. 
adicionado por elas produzidos. Cerca de $22 \%$ da amostra, distribui sob forma de dividendos a maior parte de sua riqueza gerada. A remuneração de capitais de terceiros é a mais significativa para aproximadamente $11 \%$ da amostra, ou um segmento (têxtil).

Verifica-se que as empresas catarinenses obtiveram evolução na sua riqueza, quando analisado o valor adicionado gerado. Este em 2010 era de 20,9 bilhões, sendo que em 2015 chegou a 37,5 bilhões. $\mathrm{O}$ valor adicionado teve uma pequena queda percentualmente, mas se manteve entre $13,72 \%$ (2010) e 12,77\% (2014).

Quanto à distribuição da riqueza, o valor distribuído para pessoal se destaca perante as demais vertentes. Identifica-se uma oscilação de distribuição entre impostos, taxas e contribuições, remuneração de capital de terceiros e remuneração de capitais próprios, frente aos anos analisados. Em média, a vertente destinada ao Governo (Impostos, taxas e contribuições) e Remuneração de capitais de terceiros se alternam, dependendo do ano analisado, como segunda e terceira vertente de maior distribuição. A remuneração de capitais próprios é a vertente que menos distribui riqueza, impactado principalmente por resultados negativos nas empresas alimentícias e têxteis.

Quando a análise é direcionada ao ramo de atuação das entidades, classificadas em indústria, comércio e serviços visualiza-se que segundo sua capacidade de geração de receita, indústria é o ramo que detém o maior valor adicionado e a maior receita gerada durante todo o período em análise; o comércio é o ramo que menos contribui em relação a sua receita e o que menos criou riqueza no período em análise e, o setor de serviços é o segundo em receita e distribuição do valor adicionado gerado, quando falamos em valor. Vale ressaltar que percentualmente é o ramo que mais cresceu nesses indicadores.

Sob o enfoque da geração de empregos, a maior parte da amostra informou em seus demonstrativos percentuais significativos de distribuição. A indústria é o ramo que mais empregou neste período, com número crescente de empregados. O comércio é o ramo de atividade que menos emprega com relação à amostra e o setor de serviços é o segundo colocado na geração de empregos.

Os resultados encontrados ao findar dos estudos foram limitados pela falta de informações complementares e estudos correlatos que possibilitassem comparações e, comprobações. Desta forma sugere-se a aplicação deste estudo para as demais unidades federativas, ou a toda a federação e, grupo de entidades, onde se julgue relevante à análise dos cocientes e a apropriação dos resultados encontrados.

Sob a ótica dos estudos anteriores, percebeu-se que a DVA possui uma linguagem de fácil entendimento, podendo ser analisado sob diversos aspectos, bem como é entendida como excelente instrumento de identificação de geração e distribuição de riqueza. Tem como característica fundamental evidenciar mecanismos de informação suficientes para que empresas de nível pública ou privada tomem decisões pertinentes aos níveis de políticas e justiças de distribuição da riqueza.

Diante das considerações, percebeu-se que a DVA contribui como ferramenta social e econômica, permitindo analisar o quanto cada empresa criou de riqueza e de que maneira ela distribuiu conforme suas vertentes econômicas. Além disso, em cada uma das vertentes contribui em termos: a) sociais, quando verificado pelo trabalhador o retorno por este; b) financeiro: quando analisado pelo investidor a remuneração recebida, e c) econômico: quanto à empresa contribui em forma de tributos para o desenvolvimento de uma determinada região ou sociedade. Ao tempo que também nos possibilita comparar quais dos agentes econômicos obtiveram a maior parcela de distribuição, quando analisados de forma global, por ramo de atuação e por segmento. Ainda, é aconselhável e recomenda-se que esse demonstrativo possa aumentar seu leque de informações aos usuários, podendo a mesma ser elaborada por regiões e por Estados, pois as informações geradas remetem a sede da empresa, todavia, é perceptível que nem sempre podemos considerá-la como fonte única geradora de riqueza, visto que as

Revista Ambiente Contábil - ISSN 2176-9036 - UFRN - Natal-RN. v. 10. n. 1, p. 200 - 222, jan./jun. 2018. 
empresas possuem unidades fabris ou administrativas fora do Estado da sua sede. Sugere-se que sejam realizados estudos complementares e que seja aplicado em amostra de maior abrangência.

Esse artigo contribui com a visualização e observância das distribuições realizadas pelas empresas de capital aberto de Santa Catarina listadas na BM\&FBOVESPA nos anos de 2010 a 2015, fornecendo dados que podem servir como ponto inicial de novas análises nos anos subsequentes ou comparação da evolução histórica dos indicadores pelos futuros trabalhos realizados sobre o mesmo enfoque.

\section{REFERÊNCIAS}

ASSAF NETO, Alexandre. Estrutura e análise de balanços: um enfoque econômico financeiro. 9. ed. São Paulo: Atlas, 2010.

BM\&FBOVESPA (São Paulo). Sobre a BM\&FBOVESPA. 2016a. Disponível em: <http://www.bmfbovespa.com.br/pt_br/a-bm-fbovespa/institucional/quem-somos/>. Acesso em: 19 ago. 2016.

BM\&FBOVESPA (São Paulo). Critério de classificação. 2016b. Disponível em: < http://www.bmfbovespa.com.br/pt_br/produtos/listados-a-vista-e-derivativos/rendavariavel/empresas-listadas/criterio-de-classificacao/>. Acesso em: 19 ago. 2016.

BM\&FBOVESPA (São Paulo). Segmento de Listagem. 2016c. Disponível em: http://www.bmfbovespa.com.br/pt_br/listagem/acoes/segmentos-de-listagem/nivel-2/>. Acesso em: 19 ago. 2016.

BRASIL. Lei $\mathrm{n}^{\mathrm{o}}$ 11.638/2007. Altera e revoga dispositivos da Lei $\mathrm{n}^{\mathrm{o}} 6.404$, de 15 de dezembro de 1976, e da Lei $\mathrm{n}^{\circ}$ 6.385, de 7 de dezembro de 1976 e estende às sociedades de grande porte disposições relativas à elaboração e divulgação de demonstrações financeiras. Diário Oficial [da] República Federativa do Brasil. Brasília - DF. Disponível em: <http://www.planalto.gov.br/ccivil_03/_ato2007-2010/2007/lei/111638.htm>. Acesso em: 15 set. 2017.

COMITÊ DE PRONUNCIAMENTOS CONTÁBEIS - CPC. Pronunciamento Técnico CPC 09: demonstração do valor adicionado. Brasília, DF, 30 out. 2008b. Disponível em: <http://www.cpc.org.br/pdf/CPC_09.pdf>. Acesso em: 31 jul. 2009. Acesso em: 14 set. 2016.

CUNHA, Jacqueline Veneroso Alves da RIBEIRO, Maisa de Souza. O papel da demonstração do valor adicionado na avaliação da responsabilidade social das empresas. Disponível em: <http://www.eac.fea.usp.br/congressousp/congresso3/>. Acesso em: 15 set. 2007.

CUNHA, Jacqueline Veneroso Alves da; RIBEIRO, Maisa de Souza; SANTOS, Ariovaldo dos. A Demonstração do Valor Adicionado como Instrumento de Mensuração da Distribuição da Riqueza. Revista Contabilidade e Finanças. São Paulo, n. 37, p. 7-23, jan./abr. 2005.

DALMÁCIO, Flávia Zóboli. Indicadores para análise da Demonstração do Valor Adicionado. Revista Brasileira de Contabilidade. N. 149, p. 89-97, set./out. 2004. 
DE LUCA, Márcia Martins Mendes. A Contribuição da Demonstração do Valor Adicionado no Processo de Mensuração do PIB e em Algumas Análises Macroeconômicas. 1996. 153 f. Tese (Doutoramento em Contabilidade e Controladoria) Universidade de São Paulo, São Paulo, 1996.

ELIZARDO, Marcelo; NAIME, Laura. Paraná passou Rio Grande do Sul e se tornou 4 maior PIB entre estados. 2015. Disponível em: $<$ http://g1.globo.com/economia/noticia/2015/11/parana-passou-rio-grande-do-sul-e-se-tornou4-maior-pib-entre-estados.html>. Acesso em: 17 ago. 2016.

FONSECA, João José Saraiva da. Metodologia da Pesquisa Científica. Fortaleza: Uece, 2002. 127 p. Disponível em:< http://www.ia.ufrrj.br/ppgea/conteudo/conteudo-20121/1SF/Sandra/apostilaMetodologia.pdf>. Acesso em: 05 maio. 2016.

GERHARDT, Tatiana Engel; SILVEIRA, Denise Tolfo (Org.). Métodos de Pesquisas. Porto

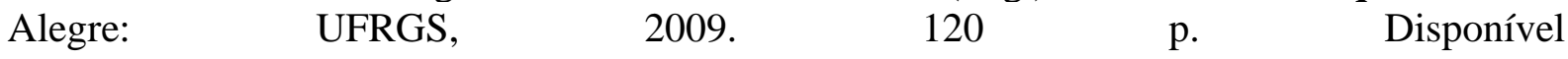
em:<http://www.ufrgs.br/cursopgdr/downloadsSerie/derad005.pdf $>$. Acesso em: 01 maio. 2016.

GIL, Antônio Carlos. Como elaborar projetos de pesquisa. 3. ed. São Paulo: Atlas, 1991. Disponível em: < http://cleilsonfernandes.com/downloads/Como-Elaborar-Um-Projeto-DePesquisa.pdf>. Acesso em: 01 maio. 2016.

IUDÍCIBUS, Sérgio de; MARTINS, Eliseu; GELBECK, Ernesto Rubens. Manual de Contabilidade Societária. 1. ed. São Paulo: Atlas, 2010.

KROETZ, César Eduardo Stevens. Balanço Social: teoria e prática. São Paulo: Atlas, 2000.

PEGORARO, Delvan Guerreiro; LORENZETT, Daniel Benitti; FRANCESCHI, Franciéli Rosa de; COSTA, Vanessa de Matos da; ROSSATO, Marivane Vestena. A demonstração do Valor Adicionado (DVA). In: Simpósio de Ensino, Pesquisa e Extensão, XIV, 2010, Santa Maria. Anais... Santa Maria: SEPE, 2010.

SANTOS, Ariovaldo dos. Demonstração contábil do Valor Adicionado - DVA - Um instrumento para medição da geração e distribuição de riqueza das empresas. Tese de Livre Docência - Faculdade de Economia e Contabilidade da Universidade de São Paulo. São Paulo: FEA/USP, 1999.

SANTOS, Ariovaldo dos. Demonstração do Valor Adicionado: Como elaborar e analisar a DVA. São Paulo: Atlas, 2003.

SEBRAE, Santa Catarina em Números: Santa Catarina. Florianópolis: SEBRAE/SC, 2013. $150 \quad$ p. Disponível em: <http://www.sebrae.com.br/Sebrae/Portal\%20Sebrae/Anexos/Relatorio\%20Estadual. pdf> Acesso em: 20 agosto. 2016.

SILVA, Manoel Rubim da; MARQUES, Mary Amália Castro Rocha. Demonstração do valor adicionado (DVA): um instrumento para aferição da carga tributária por unidade ou segmentos produtivos. Revista da Receita Federal: estudos tributários e aduaneiros. Brasília DF, v.1, n.2, p. 217-232, jan./jul. 2015. 
SIMONSEN, Mário Henrique; CYSNE, Rubens Penha. Macroeconomia. São Paulo: Atlas, 1995 apud SANTOS, Hmenon Carvalho. Análise da demonstração do valor adicionado: um enfoque gerencial. 1999. 42 f. Monografia (Graduação em Ciências Contábeis) Departamento de Ciências Contábeis, Universidade Federal de Pernambuco.

SOUSA, Edmilson Patrocínio de. Demonstração do valor adicionado - evidenciando a distribuição da riqueza gerada pela empresa. Revista Brasileira de Contabilidade. N. 142, p. 21-27, jul./ago. 2003.

TRIVIÑOS, Augusto Nibaldo Silva. Introdução à pesquisa em ciências sociais: a pesquisa qualitativa em educação. São Paulo: Atlas, 1987. 